The

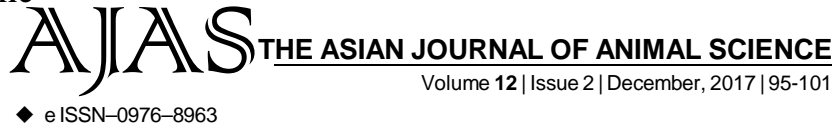

DOI : 10.15740/HAS/TAJAS/12.2/95-101

Visit us | www.researchjournal.co.in

RESEARCH ARTICLE........

\title{
Study on self-confidence of dairy farmers and relationship with their personal attributes
}

\author{
RAKESH AHUJA, S.P. SINGH, S. S. SANGWAN, GAUTAM AND ANIKA MALIK $\ldots \ldots \ldots \ldots \ldots \ldots \ldots$
}

Author for Corresponding -

\section{ANIKA MALIK}

Department of Veterinary and Animal Husbandry Extension

Education, College of Veterinary

Sciences, Lala Lajput Rai

University of Veterinary and

Animal Sciences, HISAR

(HARYANA) INDIA

Email : anikadhundwal@

gmail.com

See end of the article for

Coopted authors'

\begin{abstract}
Dairy enterprise could play a more constructive role in promoting rural welfare and reducing poverty by generating employment at farm level is increasingly being recognized. The present study was conducted on 160 dairy farmers selected from 12 villages of Hisar and Jind districts of Haryana to assess the self-confidence among dairy entrepreneurs about animal husbandry practices. Self-confidence was measured by using innovative scale which consisted of five practices in respect of the dairy management. The respondents were grouped into three categories namely low, medium and high level of self-confidence using mean and one standard deviation. The data were collected through pre-tested structured interview schedule by holding personal interview with the dairy farmers during 2014-15. The overall analysis revealed that 36.88 per cent of dairy farmers had medium level of self-confidence while 33.1 per cent and 30 per cent of dairy farmers were having low and high level of selfconfidence, respectively. It is evident from the correlation analysis that educational qualification, size of land holding, annual income, caste, dairy farming experience, extension contact, social participation, mass media exposure, economic motivation, scientific orientation, attitude towards dairy farming and market orientation showed positive and significant relationship $(\mathrm{P}<1)$ with self-confidence of dairy farmers while age also having significant but negative correlation with self-confidence of dairy farmers. The negative correlation of age with self-confidence of dairy farmers may be attributed to the reason that with the advancing age farmers become more inclined towards traditional practices due to lack of energy, change proneness, decision making ability and progressive attitude. Almost similar results were also seen in case of small, medium and large categories of farmers. Further, regression analysis revealed that two independent variables namely, caste and economic motivation were found to have positive and significant values of ' $t$ ' for ' $b$ '. The multiple co-efficient determinant $\left(R^{2}\right)$ further implies that all the thirteen variables had together explained 91.25 per cent of variation towards self-confidence of dairy farmers.
\end{abstract}

KEY WORDS...... Self-confidence, Economic motivation, Scientific orientation, Dairy farmers

HOW TO CITE THIS ARTICLE - Ahuja, Rakesh, Singh, S.P., Sangwan, S.S., Gautam and Malik, Anika (2017). Study on self-confidence of dairy farmers and relationship with their personal attributes. Asian J. Animal Sci., 12(2): 95-101. DOI : 10.15740/HAS/TAJAS/12.2/95-101.

ARTICLE CHRONICLE - Received : 13.10.2017; Revised : 01.11.2017; Accepted : 15.11.2017 